\title{
Geomarketing: Desde una visión comercial a una aplicación social, en contextos metropolitanos
}

\section{Geomarketing: From a commercial vision to a social application, in metropolitan contexts.}

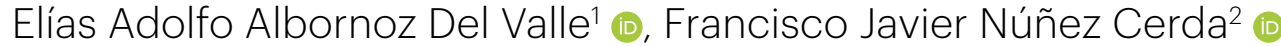 \\ y Carlos Mena Frau ${ }^{3}$ (B)
}

\begin{abstract}
RESUMEN
El geomarketing aplicado, con propósitos comerciales, aborda elementos del marketing, incorporando perspectivas espaciales, todo soportado por SIG. Analiza temáticas de mercado, colaborando a la comercialización privada de bienes y servicios, definiendo coberturas geográficas comerciales y rentabilizando dichos negocios. Dichas técnicas, también aplican al análisis y evaluación de proyectos apoyando eficazmente programas sociales organizados por el sector público u otros usuarios, satisfaciendo necesidades en comunidades urbanas: génesis del geomarketing social, una nueva orientación. Ésta busca aumentar el bienestar de los ciudadanos; ej. Localización de equipamiento educacional, salud, deportivo o soporte a la aplicación de políticas y programas a beneficiarios segmentados. Este artículo, basado en proyectos I+D+i realizados por los autores, propone una sistematización metodológica e informatizada, para aplicar geomarketing desde ambas perspectivas orientadas al usuario. Se identifica información, etapas, procesos propios y compartidos, más resultados obtenidos. Se prueba un caso comercial y otro social, en el Centro Metropolitano de Concepción, Región del Biobío, Chile.
\end{abstract}

Palabras Clave: Geomarketing, Sistemas de Información Geográfica, Análisis espacial, Planificación Urbana.

\begin{abstract}
The applied geomarketing, for commercial purposes, addresses elements of marketing, incorporating spatial perspectives, all supported by GIS. It analyzes market themes, collaborating in the private commercialization of goods and services, defining commercial geographic coverage and making these businesses profitable. These techniques also apply to the analysis and evaluation of projects effectively supporting social programs organized by the public sector or other users, meeting needs in urban communities: genesis of social geomarketing, a new orientation. It seeks to increase the welfare of citizens; Ex. Location of educational, health, sports equipment or support to the application of policies and programs to targeted beneficiaries. This article, based on I+D+i projects carried out by the authors, proposes a methodological and computerized systematization, to apply geomarketing from both perspectives oriented to the user. It identifies information, stages, own and shared processes, more results obtained. A commercial case and a social case are tried at the Centro Metropolitano de Concepción, Biobío Region, Chile.
\end{abstract}

Key Words: Geomarketing, Geographic Information Systems, Spatial Analysis, Urban planning.

Laboratorio de Economía Espacial (LEE), Departamento de Planificación y Diseño Urbano, Facultad de Arquitectura, Construcción y Diseño, Universidad del Bío - Bío. (2) Doctorado en Arquitectura y Urbanismo (DAU). Universidad del Bío - Bío. E-mail: ealborno@ubiobio.cl. ORCID: https://orcid.org/0000-0002-2305-4306

Laboratorio de Economía Espacial (LEE), Departamento de Planificación y Diseño Urbano, Facultad de Arquitectura, Construcción y Diseño, Universidad del Bío - Bío. E-mail: fnunez@ubiobio.cl. ORCID: https://orcid.org/0000-0002-2238-3861

Departamento de Gestión Forestal Ambiental, Facultad de Ciencias Forestales, Universidad de Talca. Centro de Geomática (CENGEO), Universidad de Talca. E-mail: cmena@utalca.cl. ORCID: https://orcid.org/0000-0001-7780-9092 


\section{Introducción}

\section{Del marketing tradicional al geomarkenting}

La localización e implementación de establecimientos comerciales urbanos, corresponde a la tipología de comercialización, específicamente bienes de consumo. La factibilidad de instalación ha sido evaluada, por mucho tiempo, de acuerdo a criterios de rentabilidad económica tradicionales. Incorpora herramientas de marketing para el desarrollo de estrategias de comercialización, publicidad, producto, precio y distribución. Hoy en día cada vez más, se pone de manifiesto, la necesidad de desarrollar medios de marketing eficaces y rápidos para valorar, identificar y relacionar los intercambios que existen en un espacio geográfico, entre distintitos tipos de individuos. De tal forma que ambas partes obtengan la satisfacción de sus demandas y necesidades (Esteban, 1996, citado en Chasco 2003). De esta forma el marketing busca responder interrogantes tales como: ¿Quiénes son nuestros clientes/competidores?, ¿Qué nuevos/existentes productos o servicios se desarrollan?, ¿Dónde se desarrollan/distribuyen los productos y la localización de competidores? (Beaumont, 1991). Responder a estas preguntas de forma analítica, requiere un gran procesamiento de información.

Dentro de la planificación urbana, estas interrogantes también se pueden incorporar, partiendo con la identificación y determinación de necesidades de diferentes públicos, reales como potenciales. La idea surge a través de la oferta de productos y servicios con el fin de satisfacer dichas necesidades. También se manifiesta la idea de plantear objetivos a corto y largo plazo permitiendo unir voluntades y coordinar actividades de diferentes instituciones, ya sean, comunitarias, estatales, autónomas y municipales, para conseguir "sacar a flote una ciudad" (Martínez, 2004).

En las áreas de aplicación del marketing, ya sea privado como social, al momento de incluir un sistema de información geográfico (SIG), técnicamente se transforma en una corriente de análisis denominada geomarketing. Esta disciplina incorpora técnicas que permiten analizar la realidad económico social desde un punto de vista geográfico, a través de instrumentos cartográficos y herramientas de estadística espacial (Chasco, 2003). La incorporación del SIG facilitaría dar respuesta a las preguntas esenciales del marketing, facilitando el análisis del comportamiento espacial de la información proporcionada por el consumidor o de fuentes secundarias.

Otro elemento relevante del geomarketing o de la geografía digital, es la posibilidad de generar información económica espacial, gráficamente simplificada (que contienen un gran número de datos) permitiéndonos realizar con simplicidad, análisis espaciales tradicionales extremamente complejos, hasta hace poco tiempo imposibles de realizar.

\section{Definiciones Conceptuales}

Algunos autores definen geomarketing como "una aplicación específica de economía espacial" que consiste en el tratamiento espacial de las variables del marketing, para complementarlas con la información sociológica, demográfica, económica, topográfica y variables de comportamiento, todas distribuidas en el mismo espacio (Latour y le Floc'h, 2001, p. 37-49). Sin embargo, más que una aplicación específica, el geomarketing es un campo para el estudio de conceptos, métodos y 
técnicas de análisis geográfico, relacionadas con temáticas de marketing (Amago, 2000; Moreno, 2004). Aun así, muchos estudios se limitan a describir técnicas de geocodificación y divisiones geográficas, siendo integrados y asociados con funciones estadísticas (Cliquet, 2006). Desde esta perspectiva, el marketing provee elementos que van más allá de un análisis descriptivo, pudiéndose definir estrategias relacionadas con la oferta y demanda de bienes y servicios, sin perder de vista el espacio geográfico para disponer nuevamente de stock de acuerdo a preferencias, comportamientos y hábitos económico espaciales del consumidor. Dichas definiciones provienen directamente de la literatura, sin embargo también es necesario considerar la opinión de expertos de acuerdo a su aplicación práctica y aportes en planificación urbana internacional.

El geomarketing, de acuerdo a esta visión, "es la posibilidad de prever tendencias, algo que en el marketing se usa desde hace mucho tiempo basándose en el "ojo del experto" y en algunos datos del mercado... hoy es posible localizar geográficamente tendencias, con mucha precisión dando la posibilidad a quien diseña una estrategia de comunicación o de ventas, de acceder directamente al objetivo y/o meta deseada con información de detalle. Así el geomarketing ofrece la posibilidad de relacionar una enorme cantidad de datos, dando un output simplificado que podemos comprender y tomar decisiones en base a lo que vemos. (Walter Barberis, comunicación personal, 19 de junio de 2017)

\section{Sistemas de información geográfica, planificación urbana y geomarketing}

Como se mencionó anteriormente, la masificación de los sistemas computacionales, y, con esto el avance en los SIGs; ha permitiendo gestionar, relacionar y analizar la información espacial y temática. Con lo cual se han constituido en la tecnología de preferencia que geógrafos, cartógrafos, ingenieros, arquitectos y otros profesionales, utilizan para trabajar sobre el territorio (Mena, 2005). Se estima que un $80 \%$ de las decisiones público y privadas consideran, de alguna forma, una variable de localización (Østensen, 2001). En efecto, los mapas y la construcción de cartografía temática son importantes para la variedad de profesiones que trabajan en conjunto con los gobiernos locales (Gilfoyle y Thorpe, 2004). Es de pertinencia elaborar estudios de geografía aplicada de cara a la toma de decisiones que involucren aspectos espaciales. El sector público, que se encarga de proveer bastantes servicios, debe incorporar directamente la dimensión espacial y territorial para la regulación de las necesidades de sanidad, educación, deportes, protección civil, entre otras (Moreno, 1995).

En las sociedades avanzadas el sector servicios, ha ido adquiriendo no solo un notabilísimo papel económico, sino también una importancia para el bienestar social. Este funcionamiento impone procurar un ajuste territorial entre proveedores (oferta) y usuarios consumidores (demanda), hecho que indefectiblemente les confiere un principio unificador de su despliegue espacial (Moreno, op. cit.). En este contexto, la economía ha generado grandes transformaciones dentro de las políticas urbanas de planificación, incluyendo dentro de su aplicación el marketing. Definido como una ciencia del comportamiento que explica las relaciones de intercambio, que suelen tener lugar sobre un espacio geográfico, distintos grupos de individuos, de tal manera que las partes implicadas obtengan satisfacción de sus deseos y necesidades económicas (Esteban, 1996 citado por Chasco, 2003). 


\section{Similitudes entre la gestión empresarial y gestión urbana}

Observando, existen grandes similitudes entre la gestión empresarial y la gestión urbana. Estos paralelismos están dados desde la gestión local estratégica. Ésta define a la ciudad como una organización emprendedora, encargada de producir y comercializar unos determinados bienes y servicios para satisfacer a largo plazo unas demandas y expectativas propias y ajenas; en particular las demandas relacionadas con la localización de los individuos y las organizaciones productivas (Menta, 2001). El alcalde y el equipo de gobierno forman el elemento central, teniendo que proporcionar a sus habitantes, visitantes, trabajadores, inversionistas y a empresas los distintos bienes, productos y servicios que la ciudad es capaz de proporcionar, administrando y gestionando eficientemente los recursos disponibles.

Esta orientación, al cliente, como tendencia del marketing convencional surgida en la década de los 90', se aplica directamente a la gestión de las ciudades, compitiendo para la satisfacción de las diferentes necesidades que poseen los heterogéneos grupos de usuarios, como lo son los visitantes, residentes, empresas y trabajadores, lo que ha dado origen al Marketing de Ciudades (Elizagarate, 2003). Sin embargo, concebir solamente de esta forma la ciudad, implica una política de economización de la totalidad del campo social. Este moderno arte de gobernar, llamado gestión estratégica, destruye toda una serie de representaciones de la ciudad como organismo, como agregación de familias, como asociación de vecinos, etc. para englobar todo, bajo la forma empresa y según la lógica de relación del mercado, la oferta y la demanda. (Sacchi, 2010).

Atendiendo a la crítica anterior, es necesario ir más allá del beneficio económico privado, a través de una única función proveedora de bienes y servicios propia de las empresas. Socialmente estas ideas también se pueden orientar para dar respuesta a las preguntas esenciales del marketing, pero en este caso, desde una visión emanada desde lo público. Estas ideas se plantean para dar respuestas, a nivel administrativo, que garanticen la entrega de servicios a los ciudadanos. En este caso se privilegia, por ejemplo, propiciar cambios de conducta del habitante, derivados de diagnósticos urbanos frente a situaciones de riesgo y vulnerabilidad. (Pérez, 2006, citando a Andreasen, 1994). Lo anterior explica la génesis conceptual del marketing social, como una adaptación del marketing comercial, con el fin de crear programas y proyectos para influir en el comportamiento voluntario de un grupo social meta, mejorando su bienestar y el de la sociedad en general. Esta corriente, incorpora la idea de alejarse del beneficio económico privado, de esta forma el objetivo del marketing social es el beneficio para la sociedad en su conjunto.

\section{Contribuciones del geomarketing}

De acuerdo a tales antecedentes, el geomarketing es aplicable al marketing privado y social, aportando elementos económicos espaciales claves para la evaluación de proyectos e implementación de estrategias de desarrollo renovadas, conforme a las nuevas tecnologías de la información disponibles. Específicamente se identifican tres grandes aportes, planteados inicialmente por Escobar-Moreno (2015) y complementados por los autores: a) Desarrollar un análisis geográfico permite tener un mayor conocimiento del mercado potencial mediante la identificación de zonas de influencia, ubicación de la competencia y establecimiento de puntos óptimos de venta y entrega de servicios, de acuerdo al comportamiento espacial de los datos de mercado y necesidades sociales; b) De acuerdo a la demanda real y potencial según el comportamiento social 
del consumidor. En términos generales, el geomarketing hace posible una evaluación del uso de la infraestructura urbana y/o servicios relacionados, pudiéndose idear planes que integren un análisis de costos de desplazamiento. Considerando la ubicación geográfica de acuerdo al tipo de industria o actividad económica a desarrollar; c) Finalmente, permite una mejor planificación a nivel logístico, disminuyéndose los tiempos de distribución y/o recorrido tanto de clientes potenciales como de la organización, pues a partir de las características del área de análisis, se logra determinar las vías de accesos y los tiempos de para la obtención de un bien y/o servicio.

\section{Aspectos metodológicos generales para la aplicación de geomarketing comercial y social}

\section{Elementos y requerimientos de un sistema de información geográfica}

Los datos e información necesaria para aplicar geomarketing, a través de un SIG, provienen de diversas fuentes, y constituye el eje vertebrador de la estructura del sistema, siendo el soporte para el almacenamiento de la información espacial (Mena, 2005). Éstos se componen de datos alfanuméricos los cuales pueden ser internos, propios de la organización, como también externos. Éstos corresponden temáticas similares y complementarias (Chasco, 2009). Los datos, generalmente se almacenan como atributos, representando variables simbolizadas a través de cartografía digital. Específicamente esta es una de las estrategias para representar, desde una perspectiva espacial, los cuatro elementos del marketing-mix: producto, comunicación, distribución y precio (Chasco, 2003).

Los componentes estratégicos del marketing están dados por el espacio geográfico, teniendo roles de difusión. En este contexto se señalan cuatro tipos de roles del espacio: demográfico, económico, sociológico y geográfico (Latour y le Floc'h, 2001). Para cada uno de estos roles existen datos representativos que son usados como variables de comportamiento para generar indicadores de medición. La relación entre estos espacios, es proporcionada por mapas, gracias a su factor de unidad, permitiendo interrelacionar variables e información para generar un SIG. Los componentes de los diferentes espacios son los siguientes:

Cuadro N¹: Roles del espacio geográfico.

\begin{tabular}{|l|l|}
\hline Espacio & \multicolumn{1}{|c|}{ Datos Geográficos Asociados } \\
\hline Demográfico & $\begin{array}{l}\text { Concentración y características de población en zonas urbanas y zonas rura- } \\
\text { les. }\end{array}$ \\
\hline Económico & Producción (actividades económicas), distribución y operaciones comerciales. \\
\hline Sociológico & $\begin{array}{l}\text { Organización social, clasificaciones, cambios en los grupos de personas, zo- } \\
\text { nas turísticas, periféricas, lugares de vegetación, protección, regulación }\end{array}$ \\
\hline Geográfico & $\begin{array}{l}\text { Posicionamientos, límites administrativos, límites naturales, límites de habita- } \\
\text { bilidad y la topografía del terreno. }\end{array}$ \\
\hline
\end{tabular}

Fuente: Elaboración Propia, a partir de Latour y le Floc’h.

Los datos geográficos distinguen tres componentes, espacial, temático y temporal. Éstos deben estar definidos e identificados al momento de ser analizados. Estos componentes se fun- 
damentan a través de la observación del mundo, de acuerdo a las siguientes perspectivas: la lógica formal (matemáticas), el tiempo (historia), y el espacio (geografía), (Mena, 2005:78, citando a Ruiz, 1995).

\section{Componente espacial, temático y temporal de los datos: Geodemo- grafía para aplicar geomarketing}

Componente espacial: Al momento en que existe un componente espacial en el comportamiento de los consumidores/ciudadanos ¿Cómo será realizar un análisis considerando este factor? Para responder esta pregunta existen tres cualidades fundamentales para analizar el componente espacial de los datos. El primero se refiere a la localización geográfica, la cual corresponde a la posición de los objetos en el espacio; la segunda a las propiedades espaciales, longitud, forma, superficie, área, representadas por líneas y polígonos, y una tercera es la relación topológica, constituida por conectividad y proximidad, (Gutiérrez y Gloud, 1993, citados en Mena, 2005).

Para identificar el componente espacial, es básico tener una referencia geográfica de los clientes/ciudadanos, complementándose con datos de población, viviendas, entre otros. Así la dimensión espacial se pone de manifiesto en el proceso del marketing-mix, debido a que un "producto" (bien o servicio) debe ser "comunicado" al público a través de medios promocionales así como "distribuido" en un medio de transporte para su comercialización en un punto de venta, con un "precio", que suele estar muchas veces determinado por cuestiones locacionales (Chasco, 2003). Por lo tanto, la dimensión espacial es un componente estratégico del marketing. Agregando una incidencia de cualquier localización a través del componente temático de ésta, poseyendo un rol esencial al momento de difundir cualquier estrategia, (Latour y le Floc'h, 2001).

Componente temático: El componente temático hace referencia a los atributos que definen un objeto geográfico. Las variables que constituyen la información temática, pueden ser de distinto tipo y estar medidas en distintos tipos de escala (ESRI, 2009). Un SIG, como un sistema de apoyo, requiere incluir temáticas económico espaciales que representen tendencias y/o comportamientos de los ciudadanos/consumidores de acuerdo a sus necesidades. Este comportamiento es un fenómeno variable de forma conductual, temática y espacial, por lo tanto, se pueden diferenciar en determinados estados de tiempo.

Componente temporal: De la misma forma, las áreas de mercado también sufren cambios con el tiempo, debido al dinamismo de la oferta disponible, competidores o en la demanda potencial, (Moreno, 2002). Dicha variabilidad o cambio, puede afectar exclusivamente el componente temático, sin modificar el componente espacial, pero es más habitual que los cambios afecten el componente espacial. (Mena, et al., 2005). Analizar comportamientos desde el punto de vista estadístico-espacial a través del tiempo, es fundamental al momento de requerir proyecciones sobre potenciales ciudadanos/consumidores y orientar estrategias de venta y/o desarrollo urbano.

\section{Geodemografía: Tratamiento de los datos para su utilización en el aná- lisis económico espacial y geomarketing}

Para un análisis caracterizado a través de los componentes anteriores, es posible integrar la geodemografía a los análisis de mercado. Es un discriminador esencial para determinar decisio- 
nes de amplio alcance, desde la localización comercial especifica, hasta ideas para la gestión urbana y territorial, de acuerdo a características sociodemográficas. Como definición, se conoce como "El análisis de la población por el lugar dónde viven" (Leventhal, 2016: 6, citando a Sleight, 2004). Además, al utilizar el término 'geo' implica e incluye a la geografía, por lo tanto el concepto demográfico se expande en dos principios fundamentales: a) dos personas que viven en el mismo vecindario es más probable que tengan similares características que dos personas elegidas al azar; b) los vecindarios pueden ser categorizados de acuerdo a las características de sus residentes; dos vecindarios que pertenecen a una misma categoría es probable que contengan similares tipos de habitantes, aunque puedan estar geográficamente muy separados. Estos principios implican que la información geo demográfica puede ser usada para inferir probables características, patrones y comportamientos de sus residentes (Leventhal, op. cit.).

Desde esta perspectiva, el tratamiento de los datos, una vez que éstos han sido normalizados, categorizados y puestos en un contexto geográfico según sus componentes, deben responder fielmente al fenómeno socioeconómico que se explica. Estas relaciones entre datos alfanuméricos y cartográficos tendrán que ser detectados mediante un análisis exploratorio propio de los datos espaciales (AEDE, en Chasco, 2003). AED se define como "un conjunto de herramientas gráficas y descriptivas utilizadas para el descubrimiento de patrones de comportamiento en los datos y el establecimiento de una hipótesis con la menor estructura posible" (Chasco, 2009:3, citando a Tukey, 1977). Los resultados de estos análisis permitirán culminar con éxito los estudios de marketing relativos a la localización de clientes, puntos de venta, competidores, áreas de influencia, mercado potencial, distribución sobre el espacio geográfico de un fenómeno etc.

A partir de esta integración geográfica de la información, se hace necesario evaluar técnicas de análisis exploratorio para tratar los datos, adecuándolos en las temáticas del marketing. Las técnicas tradicionales para tratar y analizar datos se contextualizan dentro de modelos territoriales, geoestadística y la econometría espacial. Algunas de estas técnicas han sido utilizadas en el tratamiento de datos. La tendencia espacial se evidencia en métodos de análisis como: mapas temáticos, dinámicos, gráficos condicionales, diagramas de dispersión, mapas de percentiles y cartogramas. (Chasco, 2009). Odriozola, Bondar, Cardozo (2008) utilizan métodos de interpolación y cálculos de densidades. Pérez (2008) menciona técnicas de estandarización y ponderación de datos. Mena (2005) agrega la recuperación por condición geométrica, transformaciones de proyecciones cartográficas, atenuación de bordes y edición de elementos gráficos, entre otras.

\section{Síntesis metodológica y propuesta de sistematización:}

El procedimiento metodológico general identificado a través del estudio de la literatura actual disponible, se esquematiza y resume en la figura $\mathrm{N}^{\circ} 1$.

La figura $\mathrm{N}^{0} 1$ representa y muestra las fases que teóricamente el geomarketing utiliza desde una perspectiva privada y/o social. (Beaumont, 1991; Friedman, 2000 Biere y García, 2000; Moreno-Jimenez, 2002; Pérez, 2008; Chasco, 2003-2009; Odriozola y Falcón, 2007; Odriozola, Bondar, Cardozo, 2008; Fu-Yung, 2013; Grekousis, 2013; Roşu, 2013; Escobar, 2015; Vega, 2015; Baviera-Puig, 2016) entre otros. 
Figura N¹

Metodología general

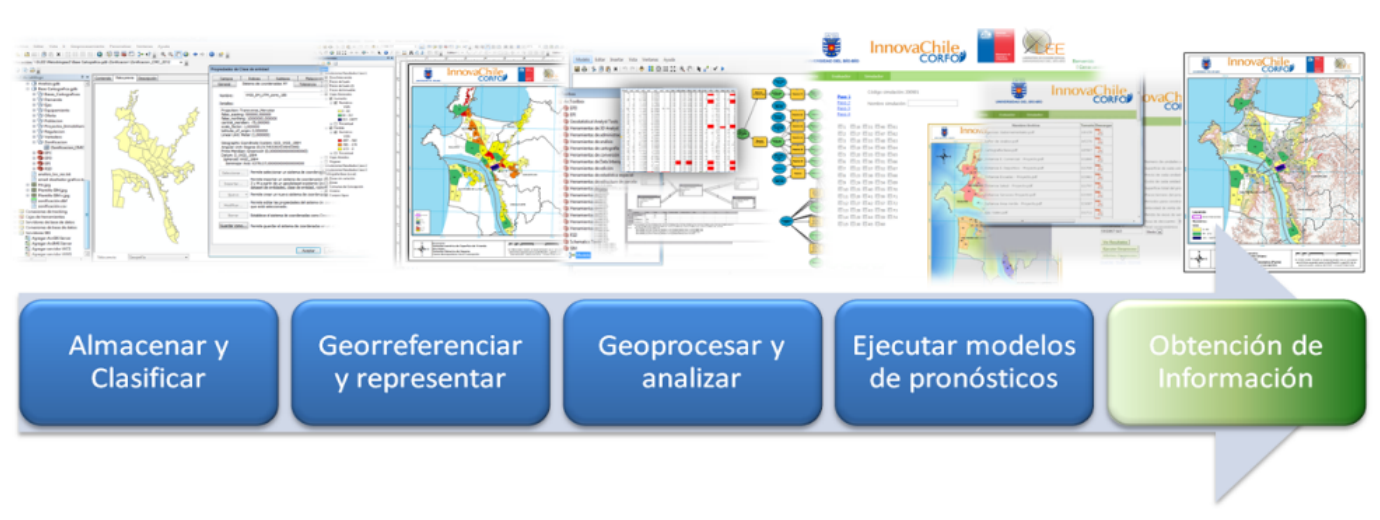

Fuente: Elaboración propia.

Sobre la base de la metodología general del geomarketing y del desarrollo experimental propio, realizado mediante prototipos específicos, los autores proponen la siguiente sistematización. Integra componentes, etapas e información, identificadas de manera no exhaustiva, para la aplicación de geomarketing comercial y social bajo un mismo procedimiento analítico e informático. En el Cuadro $\mathrm{N}^{\circ} 2$, se identifican elementos propios de cada tipo de geomarketing y aquellos que son comunes. Posteriormente se genera un diseño informático, basado en el usuario final de un SIG.

\begin{tabular}{|c|c|c|c|c|}
\hline \multicolumn{5}{|c|}{ Cuadro $\mathrm{N}^{\circ} 2$} \\
\hline & COMPONENTE & $\begin{array}{l}\text { GEOMARKETING } \\
\text { COMERCIAL }\end{array}$ & AMBOS & $\begin{array}{l}\text { GEOMARKETING } \\
\text { SOCIAL }\end{array}$ \\
\hline & Perspectiva & Privada & & Social/Pública \\
\hline & Aplicación & Proyectos & & $\begin{array}{l}\text { Proyectos/ } \\
\text { Programas }\end{array}$ \\
\hline & Usuario & $\begin{array}{l}\text { Consultor/ } \\
\text { Empresario }\end{array}$ & & $\begin{array}{c}\text { Servicio Público/ } \\
\text { ONG }\end{array}$ \\
\hline & Objeto & Cliente & & Ciudadano \\
\hline & Objetivo & Rentabilidad & & Bienestar \\
\hline & $\begin{array}{l}\text { Información de } \\
\text { Entrada }\end{array}$ & $\begin{array}{c}\text {-Localización } \\
\text { establecimiento } \\
\text { comercial } \\
\text {-Bienes y servicios a } \\
\text { comercializar }\end{array}$ & & $\begin{array}{l}\text {-Localización } \\
\text { equipamiento, } \\
\text { servicios, } \\
\text { aplicación de } \\
\text { programas. } \\
\text {-Servicios a brindar }\end{array}$ \\
\hline & Área Geográfica & Cobertura Comercial & & Cobertura Social \\
\hline \multicolumn{5}{|l|}{ ETAPAS } \\
\hline $\begin{array}{l}\text { Almacenar y } \\
\text { Clasificar: }\end{array}$ & $\begin{array}{c}\text { Estructura de los } \\
\text { Datos }\end{array}$ & & \begin{tabular}{|l|} 
Base de datos espa- \\
cial única a partir de \\
una infraestructura de \\
datos espaciales (IDE) \\
homologada según es- \\
tándares y normas de \\
información espacial
\end{tabular} & \\
\hline
\end{tabular}




\begin{tabular}{|c|c|c|c|c|}
\hline & COMPONENTE & $\begin{array}{l}\text { GEOMARKETING } \\
\text { COMERCIAL }\end{array}$ & AMBOS & $\begin{array}{c}\text { GEOMARKETING } \\
\text { SOCIAL }\end{array}$ \\
\hline $\begin{array}{l}\text { Georreferenciar } \\
\text { y representar: }\end{array}$ & $\begin{array}{l}\text { Información } \\
\text { Básica } \\
\text { Georreferenciada }\end{array}$ & & $\begin{array}{l}\text {-Planta Urbana } \\
\text {-Equipamiento } \\
\text {-Vialidad y Transporte } \\
\text {-Sociodemografía } \\
\text {-Planificación Urbana } \\
\text {-Clasificación Socio } \\
\text { Profesional } \\
\text {-Precios y Usos de } \\
\text { Suelo }\end{array}$ & \\
\hline $\begin{array}{l}\text { Geoprocesos y } \\
\text { Análisis: }\end{array}$ & $\begin{array}{l}\text { Procesos } \\
\text { específicos }\end{array}$ & & $\begin{array}{l}\text {-Análisis Espacial } \\
\text {-Formulación y aplica- } \\
\text { ción de criterios espa- } \\
\text { ciales }\end{array}$ & \\
\hline $\begin{array}{l}\text { Análisis y } \\
\text { modelos de } \\
\text { pronósticos }\end{array}$ & $\begin{array}{l}\text { Técnicas } \\
\text { específicas }\end{array}$ & $\begin{array}{l}\text {-Análisis de Mercado } \\
\text {-Análisis de Accesibi- } \\
\text { lidad } \\
\text {-Ev. Privada de pro- } \\
\text { yectos }\end{array}$ & $\begin{array}{l}\text {-Geo Estadística } \\
\text {-Econometría Espacial } \\
\text {-Análisis de Localiza- } \\
\text { ción } \\
\text {-Geodemografía }\end{array}$ & $\begin{array}{l}\text {-Estudios de Movi- } \\
\text { lidad } \\
\text {-Valoración } \\
\text {-Ev social de pro- } \\
\text { yectos }\end{array}$ \\
\hline $\begin{array}{l}\text { Almacenar y } \\
\text { clasificar: }\end{array}$ & $\begin{array}{l}\text { Información } \\
\text { Específica }\end{array}$ & $\begin{array}{l}\text {-Usos de Suelo } \\
\text {-Localización de la } \\
\text { competencia } \\
\text {-Segmentos de clien- } \\
\text { tes } \\
\text { Atracción comercial } \\
\end{array}$ & & $\begin{array}{l}\text { - Usos de suelo } \\
\text {-Segmentos de Be- } \\
\text { neficiarios } \\
\text {-Accesibilidad a ser- } \\
\text { vicios }\end{array}$ \\
\hline $\begin{array}{l}\text { Obtención de } \\
\text { Información: }\end{array}$ & Resultados & $\begin{array}{l}-\mathrm{N}^{\circ} \text {, localización y } \\
\text { características de } \\
\text { clientes } \\
\text {-Disposición a pagar } \\
\end{array}$ & & $\begin{array}{l}-\mathrm{N}^{\circ} \text {, localización y } \\
\text { características de } \\
\text { beneficiarios } \\
\text {-Valoración Social }\end{array}$ \\
\hline $\begin{array}{l}\text { Obtención de } \\
\text { Información: }\end{array}$ & $\begin{array}{l}\text { Criterios de } \\
\text { Decisión }\end{array}$ & $\begin{array}{l}\text {-VAN Privado } \\
\text {-Ventas por cliente }\end{array}$ & & $\begin{array}{l}\text {-VAN Social } \\
\text {-Costo por usuario }\end{array}$ \\
\hline
\end{tabular}

Fuente: Elaboración Propia

\section{Procedimiento informático}

A efectos de integrar, automatizar y aplicar la metodología general planteada, utilizando las potencialidades de los paquetes SIG, se diseñó un procedimiento informático. Éste contempla información, procesos, resultados y visualización, todo soportado por un entorno de trabajo orientado al usuario receptor. El objetivo de este desarrollo es analizar bajo una misma instancia de aplicación de geomarketing casos privados y/o sociales.

Las ventajas de aplicar un entorno de trabajo, soportado por un SIG, para la evaluación de iniciativas urbanas privadas o sociales, a través del geomarketing, son la objetividad y la transparencia para automatizar procedimientos, visualizar información y resultados. Se obtiene una perspectiva espacial, para un gran rango de datos, así como la simplificación de las complejas relaciones de éstos, a través de la visualización en mapas digitales interactivos. Este procedimiento es esquematizado en Figura $\mathrm{N}^{\circ} 2$. 
Figura $\mathrm{N}^{\circ} 2$

Procedimiento y elementos informáticos de un sistema de geomarketing.

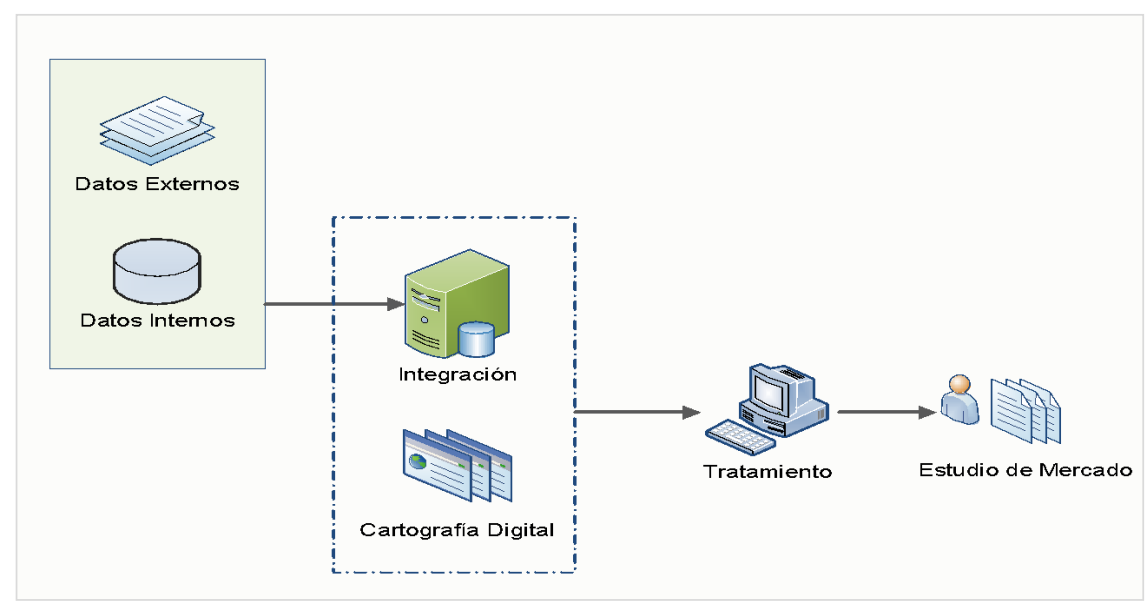

Fuente: Elaboración propia.

El procedimiento contempla las siguientes etapas: Implementación de base de datos (datos internos y externos); Integración de información y cartografía; Tratamiento de la información; Análisis espacial automatizado: Estudio de mercado.

Implementación de Base de datos: De acuerdo al cuadro $N^{\circ} 2$, una base de datos única, de una misma zona geográfica, puede alimentar ambos enfoques del geomarketing. De esta forma, en una primera etapa se detectaron relaciones a través del análisis exploratorio propio de datos espaciales. Identificando la información alfanumérica disponible en coberturas vectoriales shape. Se utilizó el SIG ArcGIS $10^{\circledR}$ para evaluar, analizar y procesar las capas de información digital e identificar los datasets de trabajo dentro del sistema de información geográfica. En una segunda etapa se dispusieron coberturas digitales. Se evaluaron y analizaron sus características temáticas para ser utilizadas en la representación geográfica de los siguientes elementos cartográficos: modelo de elevación de terreno (TIN), polígonos representativos de los límites comunales, manzanas, caracterización de población, comercio, equipamiento, servicios entre otros.

Integración de la información: A través de la georreferenciación se introdujo el posicionamiento espacial de las entidades que carecían de este atributo, bajo localización geográfica única y bien definida en un sistema de coordenadas y datum específicos, procesados a través de SIG. Lo anterior es determinante al momento de crear el método de integración de la información a través de una base de datos espacial. La geodatabase es la estructura de datos nativa para ArcGIS y es el formato de datos principal que se utiliza para la edición y administración. Es el almacenamiento físico de la información geográfica, que principalmente utiliza un sistema de administración de bases de datos (DBMS) o un sistema de archivos. Cuenta con un modelo de información integral para representar y administrar información geográfica. Este modelo de información integral se implementa como una serie de tablas que almacenan clases de entidad, datasets ráster y atributos. Esto permite trabajar con la geodatabase, e incluye el trabajo con shapefiles, archivos de dibujo asistido por ordenador (CAD), redes irregulares de triángulos (TIN), cuadrículas, datos CAD, imágenes, archivos de lenguaje de marcado geográfico (GML) y numerosas otras fuentes de datos SIG. 
Tratamiento: En una siguiente etapa se procesaron las bases de datos según las características de los componentes alfanuméricos, considerados útiles estadísticamente, para su posterior análisis espacial. Se emplearon los siguientes métodos:

- Re-proyección de Sistema de Coordenadas: Para unificar los dataset creados y utilizarlos en un mismo sistema de coordenadas se re-proyectaron todos los datos. El sistema utilizado es WGS_1984_UTM_Zone_18S pues la estimación de error en el cálculo de posicionamiento es de $2 \mathrm{~cm}$. Además, está vigente desde 2004. Se utilizó la herramienta "proyección de datos" del módulo administración de datos en ArcToolbox de ArcGis 10.

- Interpolación de datos: se usó la extensión Geoestatistical Analyst. Estos dataset contienen información relacionada a variables contenidas como atributos. Éstos fueron necesarios para representar toda la superficie del área de análisis. Se usó para interpolar datos y llevarlos a la superficie el método (IDW). Éste es un modelo basado en métodos de interpolación determinista ya que se fundamentan en muestreos en fórmulas matemáticas que determinan la forma de la superficie resultante. La fórmula general para el método es la siguiente: $\check{Z}$ (So) $=\sum \lambda i \mathrm{Z}(\mathrm{Si})$. Este método asume que la influencia de la variable decrece con la distancia al punto muestra, creando superficies con más detalle, pero de aspecto menos continuo.

- Tratamiento de imágenes satelitales. Se procesó un set de imágenes con el software Erdas Imagine. El set de imágenes se adquirió en Digital Globe con fecha de octubre de 2010, proveniente del satélite Quickbird en modalidad pancromática y multiespectral con una resolución espacial de $0,7 \mathrm{~m}$ y $2,8 \mathrm{~m}$ respectivamente.

- Mosaico: Se organizó el set de imágenes para unirlas y crear un solo archivo representativo del área de estudio. Se utilizó el módulo DataPrep con la opción Mosaic Images y Mosaic Tool.

- $\quad$ Fusión de Imágenes: Se fusionaron las imágenes con características pancromáticas y multi-espectrales con el fin de crear un archivo de tres bandas para representar el espectro de color varadero y mantener el nivel de resolución espacial que posee el modo pancromático. Se utilizó el módulo Image Interpreter y la opción Spatial Enhancement/Resolution Merge.

Análisis espacial automatizado: Estudio de mercado. Se usó Model Biulder para crear, editar y administrar modelos espaciales. Los modelos son flujos de trabajo que encadenan secuencias automatizadas para herramientas de geoprocesamiento y suministran la salida de una herramienta a otra herramienta como entrada. Un geoproceso corresponde a una secuencia de funciones de análisis espacial que se ejecutan sobre las capas de datos para obtener nuevas capa y cartografía de salida.

- Técnicas específicas de análisis integradas a través de geoprocesamiento espacial: Para todos los análisis de agrupación, se usó el método clasificación natural breaks o Jenks, implementado en ArcGis. Este método identifica los puntos de corte entre clases mediante el algoritmo de optimización de Jenks. Esta fórmula consiste básicamente en la minimización de la suma de la varianza intraclase para obtener la máxima homogeneización (mínima dispersión) dentro de cada intervalo y la máxima dispersión entre intervalos. Para 
los usos de suelo permitidos: Se usó para configurar los usos de suelo para equipamiento comercial, según los planes reguladores comunales. Se utilizó el método intersección de contenencia, indicando si el proyecto está localizado en un área apta para su desarrollo. Programación binaria para los atributos espaciales, 1 permite, 0 no permite. Figura 3.

Figura $\mathrm{N}^{\circ} 3$

Análisis de usos de suelo permitidos.

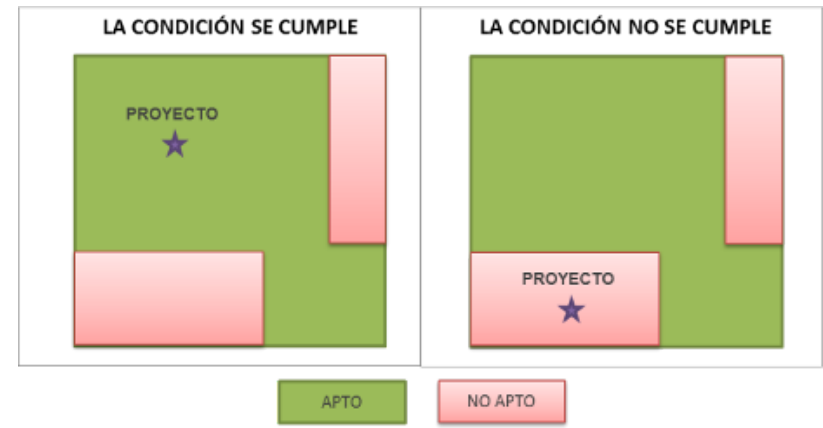

Fuente: Elaboración propia.

Determinación de área de mercado a través de Intensidad: Este principio se apoya con indicadores de magnitud relativa de la clientela potencial a captar (Moreno, 2002). Se usó la técnica SIG de interpolación de datos para establecer densidades.

Internamente la el entorno de trabajo informatizado, para la aplicación de geomarketing orientado al usuario receptor, contiene una unidad de base de datos para la evaluación integrada, la cual se completa con información, introducidos desde una instancia del usuario. Ésta recoge, sistematiza códigos y realiza los cálculos económicos más el almacenamiento de los datos. Un sistema de geoprocesos basados en programación python soportado por servicios SIG, extrae los parámetros de evaluación y entrega información espacial utilizando una geodatabase. Clasifica y procesa según los criterios expuestos. Finalmente entrega un reporte con los cálculos realizados y los mapas temáticos obtenidos según las variables involucradas. Se presenta un diagrama resumido que ilustra de forma secuencial los principales procedimientos automatizados y funciones contenidas en la aplicación. Ver figura 4.

Figura $\mathrm{N}^{\circ} 4$

Procedimiento informático.

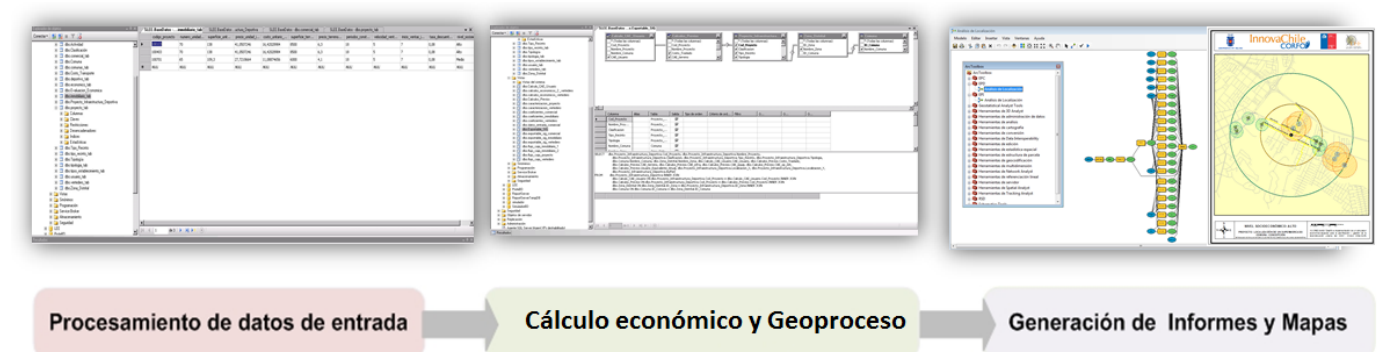

Fuente: Elaboración Propia 


\section{Procedimiento nivel usuario dentro de la plataforma informática para la aplicación de geomarketing}

Los usuarios de un SIG, como también de las aplicaciones desarrolladas en base a éste, se pueden jerarquizar en tres niveles. El primero está formado por analistas profesionales y programadores, quienes construyen el sistema. El segundo nivel, corresponde a técnicos - operadores que utilizan, mantienen y desarrollan productos a través del componente funcional del sistema. Por último, en un tercer nivel, se incluye a los usuarios receptores del SIG. El uso en este nivel, es de carácter consultivo, (Mena, 2005). A partir de este último nivel pretende aportar este trabajo, de acuerdo a las siguientes ideas: a) Los usuarios finales generalmente no son especialistas de sistemas, pero son quienes toman decisiones a partir de una amplia gama profesiones, cargos publico privados y fuentes de información disponibles; b) La información espacial desplegada ya está procesada y analizada según los requerimientos del usuario receptor, quien consulta de acuerdo a sus parámetros de decisión; c) El tiempo y los costos invertidos en la consulta de información espacial es mínimo, a diferencia de la necesidad de implementación de un sistema propio, el cual requerirá personal especializado, información específica etc. Estas justificaciones guían el objetivo para el diseño de esta plataforma, generar aplicaciones para ser usadas a nivel consultivo, previamente desarrolladas, probadas y demostrado su funcionamiento.

En este contexto, en la plataforma informática de aplicación de geomarketing, técnicamente el usuario ingresa y selecciona los datos de identificación de su proyecto, sea esto: Nombre; Clasificación: comercial o social; Tipo de Establecimiento: giro del proyecto, el usuario receptor deberá definir el tipo de establecimiento comercial; Tipología: construcción, ampliación, reposición, mejoramiento; Comuna dentro del área metropolitana.

Luego, ingresa los datos de localización, es decir, las coordenadas $X$ e $Y$ en formato UTM, el radio de influencia (valor en metros del radio circular del área de influencia) considerada en su proyecto, y guardar proyecto. Si no conoce las coordenadas UTM, las podrá seleccionar obtener con la ayuda de un mapa que indicará las coordenadas del lugar seleccionado. Con esta información la plataforma informática de aplicación de geomarketing, captura el punto de localización del proyecto en el espacio geográfico, y realiza extracción de la información soportante mediante

Figura $N^{\circ} 5$

Procedimiento de usuario.

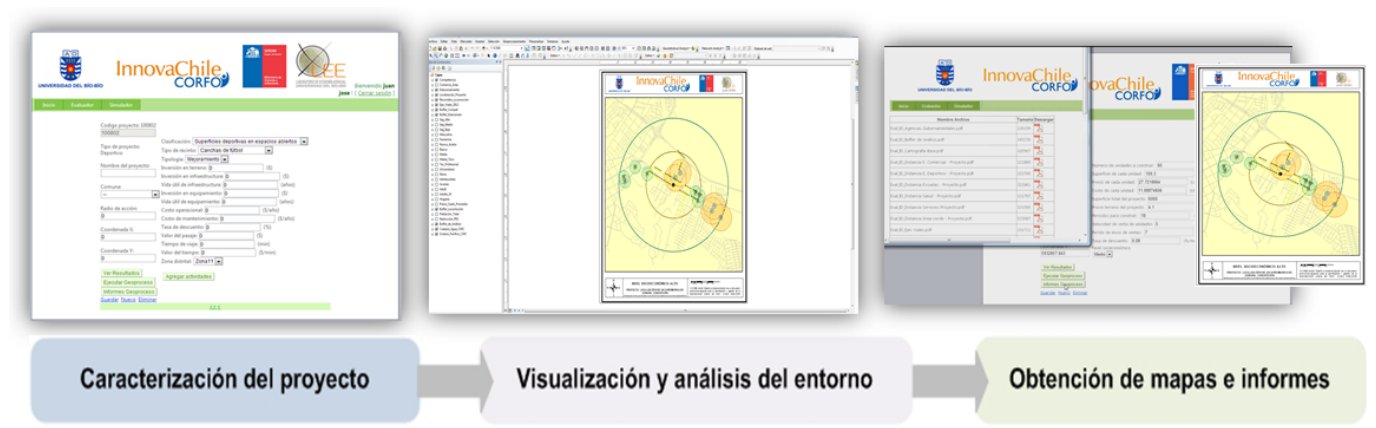

Fuente: Elaboración Propia. 
la automatización de geoprocesos. Esta información le permitirá al usuario comprobar si la localización seleccionada es adecuada, o bien, puede redefinir su población objetivo seleccionando una nueva localización y área de cobertura. Con la información de demanda, el usuario receptor puede realizar los cálculos de sus posibles ingresos, en caso que no los tenga, y posteriormente, podrá ingresar estos datos a la plataforma, la cual realizará el cálculo de los indicadores de rentabilidad, VAN, estimar cuotas de mercado y/o demandas potenciales. Figura $\mathrm{N}^{\circ} 5$.

\section{Resultados Demostrativos}

A efecto de aplicar y probar la conceptualización y sistematización señalada en el Cuadro $\mathrm{N}^{\circ} 2$, los autores lo emplean a dos casos de geomarketing, uno comercial y el otro social para el Área Metropolitana de Concepción, cuyos componentes específicos, propios y comunes se detallan en Cuadro $\mathrm{N}^{\circ} 3$. Utilizando la plataforma informática de aplicación de geomarketing diseñada, se obtienen los resultados para ambos casos de prueba.

Cuadro N³:

Componentes de las aplicaciones Geomarketing Comercial y Social.

Área Metropolitana de Concepción

\begin{tabular}{|c|c|c|c|}
\hline GEOMARKETING & COMERCIAL & COMÚN & SOCIAL \\
\hline Perspectiva & Privada & & Social/Pública \\
\hline Aplicación & $\begin{array}{l}\text { Proyecto: Instalación } \\
\text { de un nuevo } \\
\text { supermercado. }\end{array}$ & & $\begin{array}{l}\text { Proyectos/Programas de Re } \\
\text { construcción post terremotc } \\
27 \mathrm{~F}\end{array}$ \\
\hline Usuario & Consultor/Empresario & & Municipalidad de Talcahuano \\
\hline Objeto & $\begin{array}{l}\text { Captación de Cliente } \\
\text { y disposición a pagar }\end{array}$ & & $\begin{array}{l}\text { Identificación de ciudadanos } \\
\text { y necesidades (hogares afec } \\
\text { tados) }\end{array}$ \\
\hline Objetivo & Rentabilidad Privada & & Bienestar Social \\
\hline $\begin{array}{l}\text { Información de } \\
\text { Entrada }\end{array}$ & $\begin{array}{l}\text {-Localización } \\
\text { establecimiento } \\
\text { comercial } \\
\text {-Tipología de } \\
\text { construcción } \\
\text {-Bienes y servicios a } \\
\text { comercializar } \\
\end{array}$ & & $\begin{array}{l}\text {-Localización equipamientc } \\
\text { dañado, servicios afectados, } \\
\text {-Aplicación de programas } \\
\text { para potenciales subsidios. }\end{array}$ \\
\hline Área Geográfica & $\begin{array}{l}\text { Cobertura } \\
\text { geodemografíca de } \\
\text { los clientes }\end{array}$ & & $\begin{array}{l}\text { Cobertura geodemográfica } \\
\text { de la población afectada }\end{array}$ \\
\hline $\begin{array}{l}\text { Estructura de los } \\
\text { Datos }\end{array}$ & & $\begin{array}{l}\text { Base de datos espacial } \\
\text { única a partir de una in- } \\
\text { fraestructura de datos } \\
\text { espaciales (IDE) homolo- } \\
\text { gada según estándares y } \\
\text { normas de información } \\
\text { espacial } \\
\end{array}$ & \\
\hline $\begin{array}{l}\text { Información } \\
\text { Básica } \\
\text { Georreferenciada } \\
\text { (Capas Temáticas) }\end{array}$ & & $\begin{array}{l}\text {-Planta Urbana } \\
\text {-Población y vivienda } \\
\text {-Equipamiento } \\
\text {-Vialidad y Transporte } \\
\text {-Planificación Urbana } \\
\text {-Precios y Usos de Suelo }\end{array}$ & \\
\hline
\end{tabular}




\begin{tabular}{|c|c|c|c|}
\hline GEOMARKETING & COMERCIAL & COMÚN & SOCIAL \\
\hline $\begin{array}{l}\text { Procesos } \\
\text { específicos }\end{array}$ & & $\begin{array}{l}\text {-Georreferenciación y re- } \\
\text { presentación } \\
\text {-Automatización de repro- } \\
\text { cesamiento } \\
\text {-Modelos y análisis espa- } \\
\text { cial } \\
\text {-Formulación de modelos } \\
\text { de pronósticos } \\
\text {-Obtención de resultados } \\
\text { georreferenciados }\end{array}$ & \\
\hline Técnicas & $\begin{array}{l}\text {-Evaluación privada } \\
\text { de proyectos } \\
\text {-Investigación de } \\
\text { mercados } \\
\text {-Análisis de } \\
\text { accesibilidad } \\
\text {-Análisis de } \\
\text { localización }\end{array}$ & $\begin{array}{l}\text {-Geo estadística } \\
\text {-Econometría Espacial } \\
\text {-Análisis de Localización } \\
\text {-Geodemografía }\end{array}$ & $\begin{array}{l}\text {-Estudios de movilidad } \\
\text {-Valoración Social } \\
\text {-Evaluación Social de Proyec- } \\
\text { tos }\end{array}$ \\
\hline $\begin{array}{l}\text { Información } \\
\text { Específica }\end{array}$ & $\begin{array}{l}\text {-Usos de Suelo } \\
\text {-Localización de la } \\
\text { competencia } \\
\text {-Segmentos de } \\
\text { clientes } \\
\text {-Atracción comercial } \\
\text {-Servicios asociados } \\
\text { (Estacionamientos) } \\
\text {-Locomoción } \\
\text { colectiva }\end{array}$ & & $\begin{array}{l}\text {-Usos de Suelo } \\
\text {-Plan de reconstrucción del } \\
\text { borde costero } \\
\text { - Segmentos de Beneficiarios } \\
\text { - Tipo y Densidad de viviendas } \\
\text {-Características básicas y } \\
\text { económicas de los proyectos } \\
\text { de inversión para la recons- } \\
\text { trucción de Talcahuano } \\
\text {-Accesibilidad a servicios de } \\
\text { reabastecimiento }\end{array}$ \\
\hline Resultados & $\begin{array}{l}\text {-Población Total } \\
\text {-Hogares Totales } \\
\text {-Población por sexo } \\
\text {-Composición Etaria } \\
\text {-Nivel Educacional } \\
\text {-Población Laboral } \\
\text { Activa } \\
\text {-Nivel } \\
\text { Socioeconómico } \\
\text {-Disposición a pagar } \\
\text {-Localización de } \\
\text { competencia } \\
\text {-Rentabilidad } \\
\text { proyecto } \\
\end{array}$ & & $\begin{array}{l}\text {-Población Afectada } \\
\text {-Viviendas y Hogares afecta- } \\
\text { dos } \\
\text {-Características de beneficia- } \\
\text { rio } \\
\text {-Composición etaria afecta- } \\
\text { dos } \\
\text {-Nivel educacional afectados } \\
\text { - Nivel Socioeconómico de } \\
\text { afectados } \\
\text {-Superficie Comercial e In- } \\
\text { dustrial afectada } \\
\text {-Valoración Social }\end{array}$ \\
\hline $\begin{array}{l}\text { Criterios de } \\
\text { Decisión }\end{array}$ & $\begin{array}{l}\text {-VAN Privado } \\
-N^{\circ} \text { de clientes } \\
\text { potenciales } \\
\text {-Ventas por cliente y } \\
\text { tipo. }\end{array}$ & & $\begin{array}{l}\text { - No potencial de Beneficiarios } \\
\text {-Costo por usuario } \\
\text {-Valores estimativos de re- } \\
\text { construcción } \\
\text {-Estimación de Subsidios }\end{array}$ \\
\hline
\end{tabular}

Fuente: Elaboración Propia.

La descripción, información y resultados para cada uno de los casos, utilizando la plataforma y aplicando la sistematización metodológica planteada, se señala a continuación: 


\section{Aplicación de Geomarketing Comercial}

Esta aplicación tiene como objetivo apoyar al proceso de toma de decisiones relativo a la instalación de establecimientos comerciales urbanos. Proporciona información relativa a las variables espaciales para ser analizadas desde una perspectiva de geomarketing comercial. Aportan un indicador espacialmente localizado de rentabilidad privada del negocio.

Se diseñó una instancia de prueba demostrativa, estableciendo una serie de indicadores de evaluación. Los indicadores apoyarán a la toma de decisiones asociada al tipo de proyecto formulado, apuntando en relación a sus objetivos y proporcionando información para la toma de decisiones. Estos indicadores pueden ser del tipo económico, mercado y/o espacial, actuando de manera conjunta. Para el caso de un establecimiento comercial se utilizaron indicadores del tipo económico (rentabilidad comercial) de acuerdo a criterios espaciales de mercado. Se relacionan con la cercanía al mercado potencial, la localización del establecimiento en relación a servicios, competencia existente y accesibilidad para sus usuarios y clientes, finalizando con una evaluación de acuerdo a un criterio técnico-económico.

Específicamente se evaluó la instalación de un nuevo supermercado en un sector de la ciudad. Las características generales de acuerdo a la tipología del proyecto comercial, están dadas por la localización en un sector residencial, proyectando un radio de influencia. Los datos económicos considerados por el evaluador fueron de una inversión inicial, una tasa de descuento del $12 \%$ y un horizonte de evaluación de 10 años.

- Criterios de mercado: Apuntan a los aspectos sociodemográficos, socioeconómicos y de estrategias de marketing del área de estudio y de los clientes potenciales. Se usó la estrategia de determinación de la demanda potencial. Sus valores pueden ser aprovechados para verificar si la formulación del proyecto y el mercado objetivo están bien definidos. Estos criterios están asociados a variables de población total, hogares totales, composición según sexo, composición etaria y nivel educacional.

- Criterios espaciales: Se definen de acuerdo a características del proyecto. Éste debe tener una coherencia de localización y accesibilidad para con sus consumidores. La localización es un criterio imprescindible, en este caso se optó por la verificación de los usos de suelo permitidos según la normativa de los planes reguladores comunales vigentes. El segundo criterio es la distancia máxima tolerada entre la localización del proyecto y los estacionamientos. El tercer criterio corresponde a la distancia mínima tolerada que debe existir entre la localización del proyecto y la localización de la competencia.

- Criterios técnico-económicos: Se define debido a que el proyecto debe presentar una rentabilidad privada para sus operadores. Dicha rentabilidad se calculará sobre la base de sus inversiones, flujos de caja (ingresos - costos), horizonte de evaluación y tasa de descuento. Esta rentabilidad privada será medida por el VAN, cuyo valor debe ser igual o mayor que cero.

- Indicadores de evaluación: A cada uno de los criterios estará asociado por lo menos un indicador el cuál será útil como variable de decisión (cumple/no cumple) Ver cuadro $\mathrm{N}^{\circ}$ 4. Dicho indicador se definirá en relación a su metodología de cálculo o determinación, unidad de medida, fuente de la información primaria y valor de decisión. 
Cuadro N4

Indicadores de evaluación

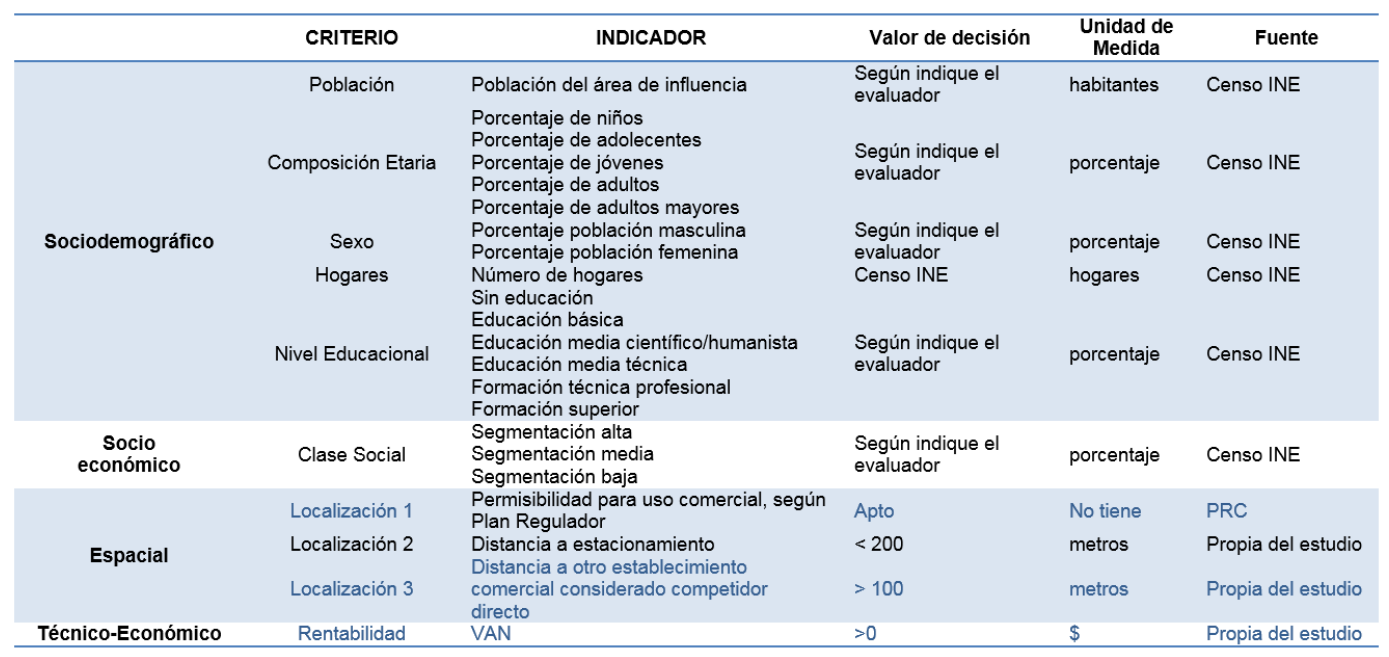

Fuente: Elaboración Propia.

De acuerdo a la programación de la aplicación, con los indicadores presentados y los datos del usuario, se obtienen los siguientes resultados económicos. Figura $\mathrm{N}^{\circ} 6$.

Figura $\mathrm{N}^{\circ} 6$

Resultados Económicos.

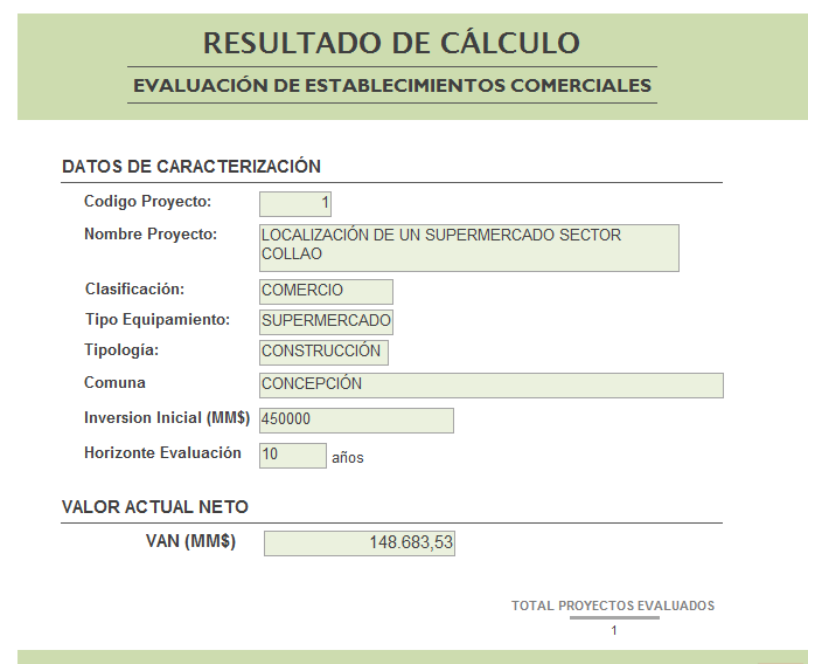

Fuente: Elaboración propia

Para la estimación de la demanda potencial a través de la segmentación realizada, se obtuvieron datos calculados de forma automática dependiendo del área de mercado que el evaluador. De la perspectiva espacial se obtuvieron los siguientes resultados, a partir de los cálculos geodemográficos. Figura $N^{\circ} 7-8$. 
Figura $\mathrm{N}^{\circ} 7$ :

Resultados económico - espaciales (demanda potencial)

\begin{tabular}{lcc}
\hline \multicolumn{1}{c}{ İtem } & Total & $\begin{array}{c}\text { Porcentaje } \\
(\%)\end{array}$ \\
\hline Población Total & 19.004 & - \\
\hline Hogares Totales & & - \\
Población Masculina & 9.195 & $48 \%$ \\
\hline Población Femenina & 9.809 & $52 \%$ \\
\hline Composición Etaria: Niños & 1.966 & $10 \%$ \\
\hline Composición Etaria: Adolecentes & 3.397 & $18 \%$ \\
\hline Composición Etaria: Jóvenes & 4.103 & $22 \%$ \\
Composición Etaria: Adulto & 7.106 & $37 \%$ \\
\hline Composición Etaria: Adulto Mayor & 2.432 & $13 \%$ \\
\hline Nivel Educacional: Ignorado & 914 & $5 \%$ \\
\hline Nivel Educacional: Nunca Asistió & 124 & $1 \%$ \\
\hline Nivel Educacional: Básica & 3.785 & $20 \%$ \\
\hline Nivel Educacional: Media CH & 5.256 & $28 \%$ \\
\hline Nivel Educacional: Media Técnica & 1.235 & $6 \%$ \\
\hline Nivel Educacional: Técnico Profesional & 1.879 & $10 \%$ \\
\hline Nivel Educacional: Universitaria & 5.811 & $31 \%$ \\
\hline Población Laboral Activa & 7.145 & \\
Nivel Socioeconómico: Alto & 2.749 & $38 \%$ \\
\hline Nivel Socioeconómico: Medio & 2.209 & $31 \%$ \\
\hline Nivel Socioeconómico: Bajo & 1.840 & $26 \%$ \\
\hline Nivel Socioeconómico: Ignorado & 347 & $5 \%$ \\
\hline
\end{tabular}

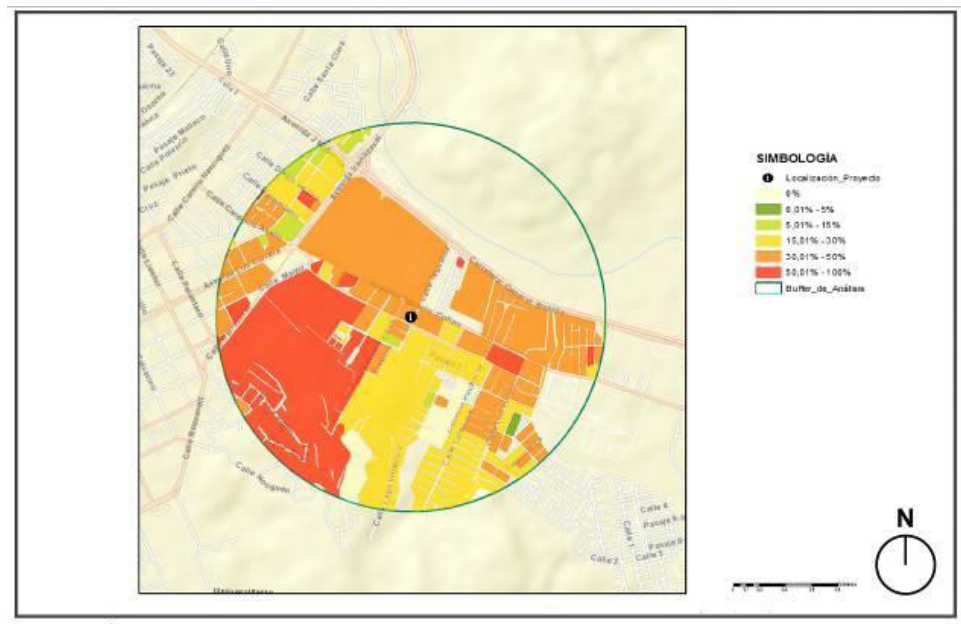

Fuente: Elaboración Propia. 
Figura $\mathrm{N}^{\circ} 8$

Resultados espaciales: competencia y usos permitidos.
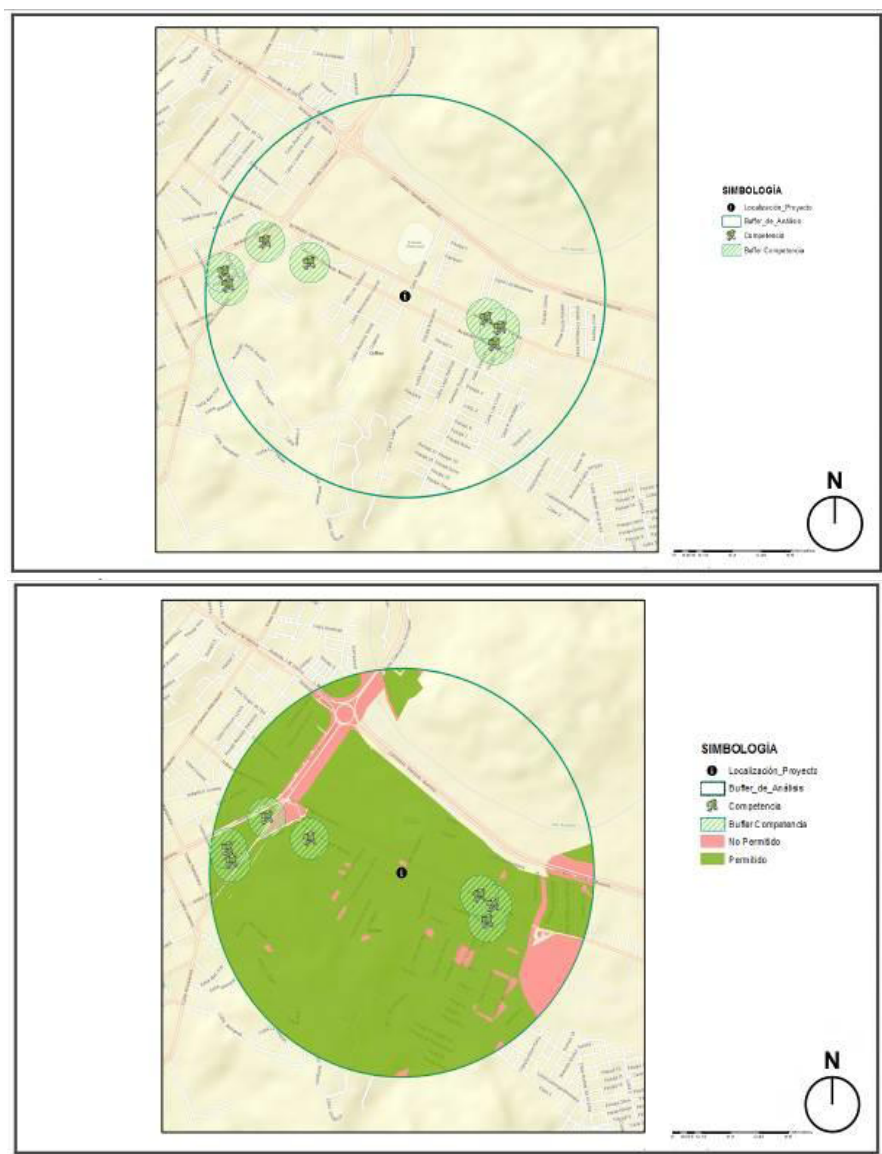

Fuente: Elaboración Propia

\section{Aplicación de Geomarketing Social}

Esta aplicación tiene como objeto el análisis de relocalización de viviendas de segmentos de población de menores ingresos y condición socioeconómica post terremoto y tsunami 27F. Además se localizaron potenciales beneficiarios para subsidios estatales y créditos especiales para PYMES comerciales e industriales.

Al momento de identificar las prioridades dentro del proceso de reconstrucción, se consideró la percepción de la ciudadanía. Para la obtención de ésta se recurrió a los resultados del "Primer encuentro ciudadano para la reconstrucción y desarrollo de Talcahuano post terremoto y tsunami 27 de Febrero 2010" (Abril, 2010). Las iniciativas que se identificaron, desde la percepción ciudadana como prioridad para la reconstrucción son tres y representan el 16,7\% del total de los votos del primer encuentro ciudadano para la reconstrucción y desarrollo. Estas iniciativas de dividen en vivienda, comercio e industria. 


\section{Vivienda: Identificación y análisis de la localización de segmentos de población de menores ingresos y condición socioeconómica}

De acuerdo a criterios de geosegmentación de demanda prensentes en Escobar-Moreno (2015), las necesidades de la sociedad o de un grupo social pueden identificarse según su condición socioeconómica. Para identificar los grupos socio económicos (GSE) en el área afectada por la inundación, se localizaron mediante el método de clasificación natural breaks o Jenks, los grupos catalogados como D y E, los cuales están clasificados como clase media baja y extrema pobreza (Puede revisarse la metodología de clasificación en: AIM, 2015). Estos grupos sociales son los que presentan una mayor vulnerabilidad, una mayor cantidad de necesidades que satisfacer, por lo tanto resulta importante para cualquier institución saber dónde están localizados para crear estrategias de marketing social. En la figura $N^{\circ} 9$ se muestra la localización de dichos segmentos.

Figura $\mathrm{N}^{\circ} 9$ :

Grupos socioeconómicos dentro del área de inundación efectiva.
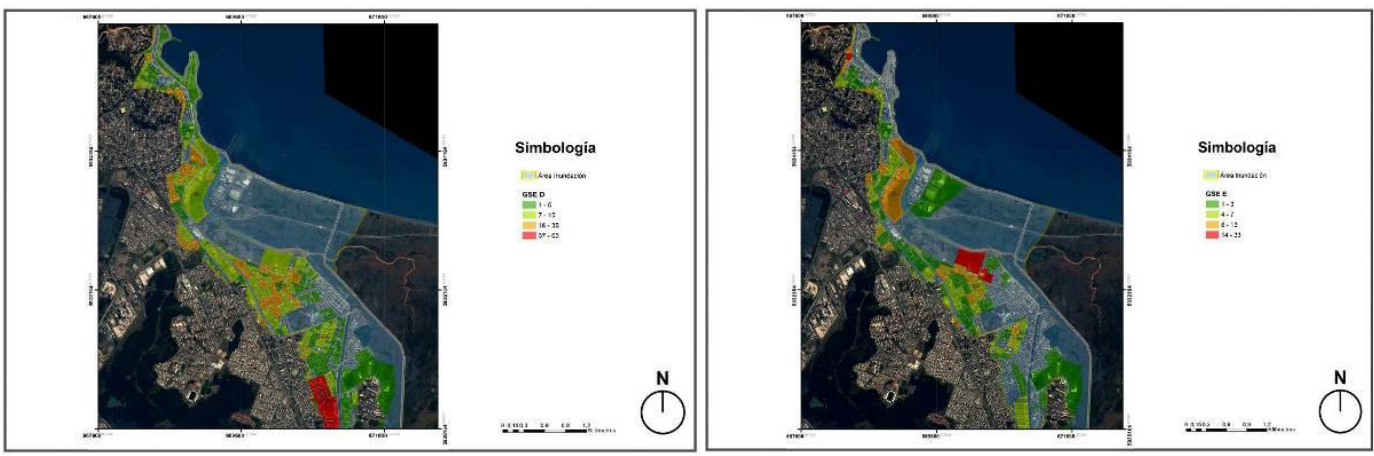

Fuente: Elaboración Propia.

Ampliando los resultados obtenidos a través del análisis espacial, se obtuvo la relación entre los sectores identificados y la densidad superficial de viviendas en la ciudad. Este resultado muestra una alta densidad de viviendas en relación a la superficie de ocupación en las áreas. Figura $N^{\circ} 10$. Se observa de color violeta una concentración de 0,02 viviendas por metro cuadrado, lo que representa un tamaño promedio aproximado para una vivienda de $50 \mathrm{~m}^{2}$.

Figura $\mathrm{N}^{\circ} 10$ :

Densidad de viviendas en área afectada.

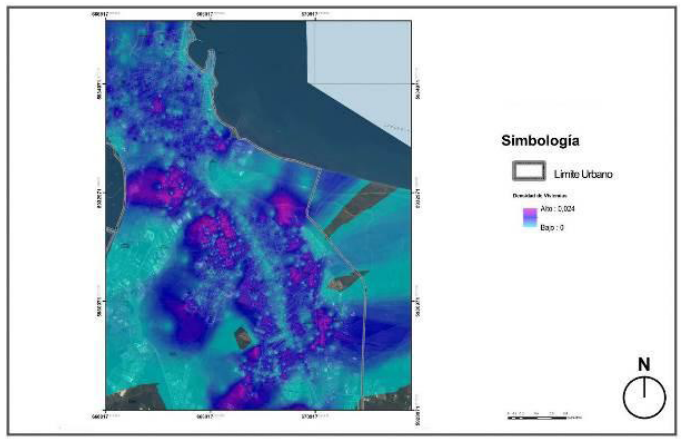

Fuente: Elaboración propia. 


\section{Comercio e Industria: Localización de potenciales subsidios estatales y créditos especiales con una mayor flexibilidad}

Para la determinación de mercado, en este caso una demanda potencial, se identificó a través de la percepción ciudadana, la necesidad de otorgar subsidios estatales a los principales afectados por el evento natural de $27 \mathrm{~F}$ en el área de comercio e industria. Eventualmente también se destaca la necesidad de la planificación de estrategias para otorgar créditos subsidiados (Albornoz, 2012).

Con el método automatizado a través de la aplicación, se utilizó la clasificación natural breaks o Jenks para identificar el sector de Talcahuano que posee una mayor concentración de construcciones comerciales (Figura $\mathrm{N}^{\circ} 11$ ). Ésta es el área que se extiende desde el Portal Los Leones al norte, limitando con el borde costero con el Océano Pacifico, al este con el cerro David Fuentes y al sur con el Canal El Moro.

Figura $\mathrm{N}^{0} 11$

Superficies de uso comercial e industrial afectadas por inundación

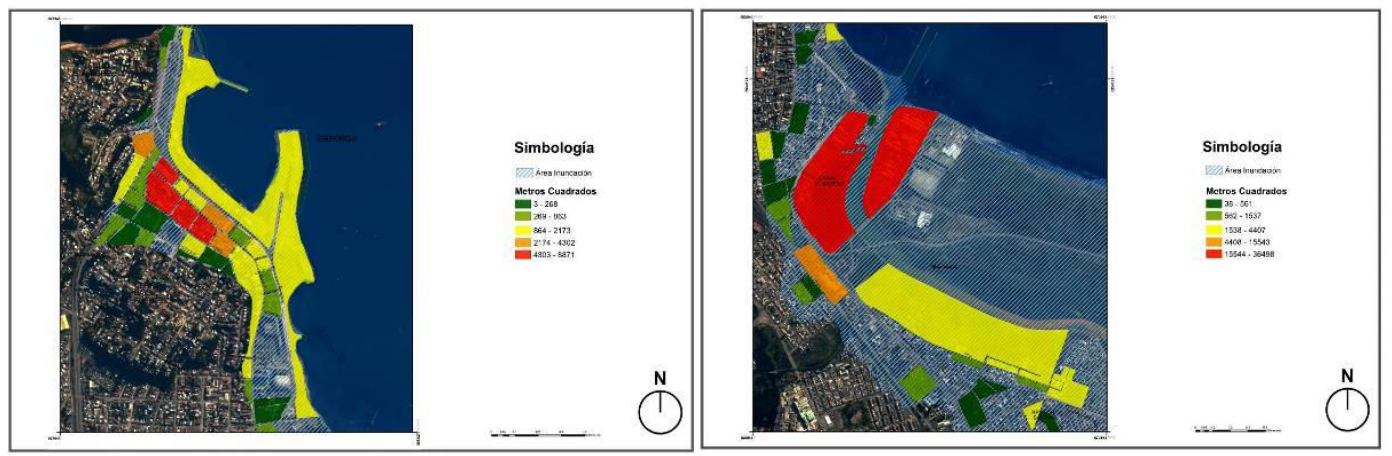

Fuente: Elaboración propia.

Estadísticamente se identificó que el 19\% de la superficie total de las construcciones destinadas a comercio podrían estar afectadas o con daños considerables. También se localizó el emplazamiento de estas construcciones, lo cual es fundamental dirigir subsidios y créditos con el fin de agilizar la reconstrucción de las superficies comerciales afectadas. De la misma forma se identificó que el $89 \%$ de la superficie total de las construcciones ubicadas en el área de inundación, destinadas a industria podrían estar afectadas o con daños considerables. También se localizaron estas construcciones, a efecto de asignar subsidios y créditos con el fin de agilizar la reconstrucción de las superficies industriales afectadas.

\section{Consideraciones finales}

Se ha demostrado la utilidad de la aplicación de nuevas técnicas, tecnologías y sistemas de información geográfica para solucionar problemas socio-económicos asociados a la gestión, planificación y ordenación territorial, desde una perspectiva comercial y social. Recordando que el ordenamiento del territorio es la proyección espacial de una estrategia de desarrollo económico 
y social; que integra por lo tanto, la planificación económica y la física a través de un enfoque interdisciplinario (Barredo, 1999. Citado en Mena, 2005).

Una de las claves es el uso de la información disponible, asignando a ésta la importancia de su componente espacial, generando análisis basados en geomarketing comercial y social a efecto de localizar en forma eficiente las necesidades, los problemas y las soluciones de los ciudadanos.

La aplicación de geomarketing facilita el análisis de información, generando respuestas en un contexto económico, social, espacial y territorial. Específicamente mediante el análisis de potenciales afectados, beneficiarios, consumidores, sectorizaciones económicas, redes de distribución de productos, calificación y espacialización de datos y representación de zonas de captación de apoyo social y económico, entre otras.

Por lo tanto, además de responder preguntas tradicionales del geomarketing comercial, se pueden integrar al análisis económico espacial, nuevas interrogantes urbanas en contextos público y social: ¿Quién/es son nuestros públicos/ciudadanos?, ¿Qué nuevos/existentes servicios e infraestructura se desarrolla?, ¿Dónde se desarrollan/conforman los ciudadanos y la localización de sus actividades/necesidades? Martínez (2004). Además, se puede dar respuesta a cuestionamientos sociales: ¿Quién/es son nuestros ciudadanos necesitados de?, ¿Qué nuevos/existentes servicios y campañas se desarrollan?, ¿Dónde se desarrollan/conforman los afectados y la localización de sus actividades/necesidades? (Pérez, 2006).

Así como el sector privado utiliza corrientemente estas técnicas y tecnologías, el sector público debe incorporar directamente la dimensión espacial y territorial para la regulación de las necesidades (Moreno, 1995). Por lo tanto la introducción y utilización de SIG en planificación urbana permite un apoyo para las políticas ciudadanas, siendo posible abordar el marketing social como estrategia para el crecimiento y fortalecimiento de iniciativas que apunten a un desarrollo social y económico de las ciudades. Constituyéndose en un importante insumo para aplicaciones más globales como es el marketing de ciudades.

El sector servicios ha ido adquiriendo una importancia para el bienestar social y este funcionamiento impone un ajuste territorial entre proveedores (oferta) y usuarios consumidores (demanda) (Moreno, op. cit.). Esta forma de analizar el espacio geográfico y económico se transforma en una nueva estrategia para identificar bienes, servicios, valores de intercambio y buscar las mejores estrategias de distribución y promoción de las ideas, orientadas hacia el desarrollo urbano. El uso y masificación de los SIG, dirigida al usuario final, ha permitido que el mundo de los negocios preste atención en las ventajas y potencialidades que poseen, y el marketing no escapa de esta influencia (Moreno, 2004). La utilización de SIG en apoyo al proceso de planificación urbana, entrega iniciativas evaluadas en contextos de geomarketing comercial y social apoya cualquier proceso de desarrollo local.

Conceptualizando teóricamente el trabajo realizado, existen definiciones metodológicas para abordar estudios de mercado de acuerdo a: la satisfacción de necesidades; una generación de productos; el establecimiento de valores de intercambio; el diseño de estrategias de promoción y distribución aplicando geomarketing comercial y social. La utilización de los SIG incluye el componente espacial dentro de los cuatro elementos del marketing mix (4p's) (Chasco, 2003). 
Esto entrega y abre nuevas posibilidades para abordar las problemáticas económico-urbanas y de comprensión sobre las aplicaciones territoriales que el geomarketing puede proyectar, no tan solo desde el punto de vista comercial, si más bien ampliarlo a temáticas sociales y urbanas.

Los anteriores conceptos podrían englobar en la siguiente relación, propuesta por los autores:

Geomarketing Comercial + Geomarketing social + Planificación urbana = Geomarketing de ciudades.

Se debe avanzar en esta dirección, sistematizando enfoques, procedimientos e información, a lo cual pretende contribuir este artículo.

\section{Referencias Bibliográficas}

ALBORNOZ, E.; MENA, C.; NÚÑEZ, F. Geomarketing para ciudades apoyo para el proceso de reconstrucción de Talcahuano, Chile. 2012. Tesis de magister. Universidad de Talca. Chile.

AMAGO, F. Logística y marketing geográfico, Barcelona, Centro Intermodal de Logística - Instituto Iberoamericano de logística. 2000, Marge Design Editors.

ASOCIACIÓN INVESTIGADORES DE MERCADO (AIM). Cómo clasificar los Grupos Socioeconómicos en Chile. Actualizado a Diciembre, 2015. Disponible en Internet: http://www.aimchile.cl/ wp-content/uploads/Presentaci\%C3\%B3n-final-AIM1.pptx

BAVIERA-PUIG, A.; BUITRAGO-VERA, J.; ESCRIBA-PEREZ. Geomarketing models in supermarket location strategies, Journal of Business Economics and Management, 2016. 17:6, 1205-1221, DOI: 10.3846/16111699.2015.1113198

BEAUMONT, J.R. An introduction to market analysis. Bath. School of Management, University of Bath, 1991.

BIERE, R; GARCIA-ALMIRALL, P. SIG orientado al Geomarketing inmobiliario en Barcelona. A: 2do Congreso Internacional Ciudad y Territorio Virtual. "2do. Congreso Internacional Ciudad y Territorio Virtual". Ediciones Universidad Bío-Bío, 2005, p. 135-141.

CLIQUET, G. Geomarketing: Methods and Strategies in Spatial Marketing. Geographical Information Systems Series, 2006.

CHASCO, C. Análisis exploratorio de datos espaciales al servicio del Geomarketing. III Seminario sobre Nuevas Tecnologías de la Investigación, en el Marketing y la Comunicación. e- Participación, 2009.

CHASCO, C. El geomarketing y la distribución comercial. Investigación y Marketing, 2003, №79, p. 6-13. 
ELIZAGARATE, V. Marketing de Ciudades. Editorial Pirámide. Madrid. 2003.

ESCOBAR-MORENO, N.; JÁCOME J.; GARCIA, G. El geomarketing como instrumento para la toma de decisiones de mercado en la organización: una caracterización preliminar de su utilidad. Espacios. 2015 Vol 36: N¹8. Pp 8.

ESRI. Business Geolnfo. GIS for Business Solutions, 2009, Spring. USA.

FU-YUNG, K.; YEN-PING, H.; RUEI-YUAN, W.; CHENG-WU, CH. Using RPC Block Adjustment models for the accuracy of environmental research, cartography and geomarketing: a new concept of cartography. Stoch Environ Res Risk Assess (2013) 27:1315-1331

FRIEDMAN, R. Marketing de Ciudades. MUNITEK. Primeras Jornadas Iberoamericanas de Marketing Municipal y Nuevas Tecnologías, 2000. Disponible en Internet: http://www.fhcm.org.ar/art/Marketing\%2Ourbano\%20de\%20ciudades\%20-\%20R.Friedman.PDF

GILFOYLE, I; THORPE, P. Geographic information management in local government, CRC Press London, 2004.

GREKOUSIS, G; HATZICHRISTOS, T. Fuzzy clustering analysis in geomarketing research. Environment and Planning B: Planning and Design 2013, volume 40, pages 95 - 116.

LATOUR, P. Y LE FLOC'H, J. Géomarketing, príncipes, méthodes et applications. Éditions d'Organisation. France, 2001.

LEVENTHAL, B. Geodemographics for Marketers. Using location analysis for research and marketing. Marketing Science Series. London, 2016.

MARTíNEZ, A. Planificación estratégica y la imagen de la ciudad. Plan Estratégico: Ciudad Real. España. I Congreso Citymarketing Elch, 2004. Disponible en internet: http://www.ciudadreal.es/ planestrategico/Planif_estr_e_imagen_ciudad_Elche.pdf

MENA, C. Geomática para la ordenación del territorio. Serie de Textos Docentes. Universidad de Talca, 2005.

MENTA, R. Aspectos estratégicos del desarrollo local. En: Transformaciones Globales, Instituciones y Políticas de desarrollo local. Homo Sapiens, Rosario. 2001

MORENO, A. Planificación y gestión de servicios a la población desde la perspectiva territorial: Algunas propuestas Metodológicas. Boletín A.G.E., 1995, № 20, p. 115-134.

MORENO-JIMÉNEZ, A. Delimitación y predicción del área de mercado para establecimientos de servicios a los consumidores con sistemas de información geográfica. Estudios Geográficos, 2002, LXIII, 247. 
MORENO, J.; PRIETO, M. ¿Cómo afecta la unidad espacial a la visualización y modelado del área de mercado con sistemas de información geográfica? Implicaciones para el Geomarketing. Estudios Geográficos, 2004, № 65. p. 617-636.

MUNICIPALIDAD DE TALCAHUANO. Primer encuentro ciudadano para la reconstrucción y desarrollo de Talcahuano post terremoto y tsunami 27 de Febrero. 2010.

ODRIOZOLA, J.; FALCÓN, V. Georreferenciación de los niveles socioeconómicos del Gran Resistencia. Facultad de Ciencias Económicas. Facultad de Humanidades. Universidad Nacional del Nordeste. "Programa la Universidad en el Medio-Cámara de Comercio". Resistencia, Chaco. 2007. Disponible en internet: http://www.unne.edu.ar/investigacion/com2008/S-002.pdf

ODIZOLA, J; BONDAR, C. Y CARDOZO, O. Geomarketing: una propuesta de localización óptima, 2008. XXIII Educa-AL. Disponible en Internet: http://blogsdelagente.com/blogfiles/mercados2009/PonenciaFinal.pdf

ØSTENSEN, O. "The Expanding Agenda of Geographic Information Systems", Boletín ISO. Julio de 2001.

PÉREZ, L. Marketing Social: Teoría y Práctica. Prentice Hall. México, 2006.

PÉREZ, R. Geomarketing en salud para ubicar oferta de servicios médicos de valor. Caso: Proyecto de investigación para ubicar una nueva oferta hospitalaria. Salud Uninorte. Barranquilla, 2008, $\mathrm{N}^{\circ}$ 24. p. 319-340.

SACCHI, E. Rosario: la experiencia política de la ciudad-empresa. Cuaderno urbano, Resistencia, v. 9, n. 9, diciembre. 2010. Disponible en internet: http://www.scielo.org.ar/scielo.php?script=sci_arttext\&pid=S1853-36552010000100004

ROŞU, L; BLĂGEANU, A.; IONUTT-CIPRIAN, I. Geomarketing - A new approach in decision marketing: case study - shopping centres in IASI. LUCRĂRILE SEMINARULUI GEOGRAFIC "DIMITRIE CANTEMIR" NR. 36, 2013.

VEGA R.; ACUÑA J.; DÍAZ M. Spatial analysis of consumer behavior in a food products market. Theoretical and Empirical Researches in Urban Management, 2015. Volume 10 Issue 1. 
